\title{
Perkiraan Geometri Sungai Bermeander dari Besaran Debit
}

\author{
Kuntjoro, Didik Harijanto, Sungkono, Saptarita, Choirul Anwar \\ Program Studi Diploma Teknik Sipil FTSP ITS, Surabaya \\ Email: kuntjoro_rivers@yahoo.co.id
}

\begin{abstract}
This paper is a preliminary study to get the correlation equation between discharge rate and meandering river geometry of Brantas River meander of Ngadiluwih Kediri. The correlation equation was derived based on the results of earlier studies that be compared with the river geometry from measurement. As reverences, there are two main equations, it have been introduced that are $\lambda=$ $106 Q \mathrm{Qm}^{0,46}$ (Carlston, 1965) and $\lambda=39 Q^{0,39}$ (Anderson, 1967). From both equations is then obtained $a$ new equation by Kuntjoro $\lambda=105 Q^{0,517}$. Three equations of the model was applied into Brantas River meander at Ngadiluwih Kediri to verify conformityof each equation. Based on standard deviation parameter, Anderson model has the worst conformity, then Carlston model, and the Kuntjoro model has best conformity with the standard deviations $\lambda=0,07, a=123,36, B=2,34$ dan $r=11,70$.
\end{abstract}

Keywords: discharge, geometry, meander, and river.

Abstrak

\begin{abstract}
Makalah ini adalah kajian awal untuk mendapatkan korelasi antara debit dengan geometri sungai bermeander pada meander sungai Brantas di Ngadiluwih Kediri. Korelasi tersebut diturunkan berdasarkan persamaan-persamaan hasil kajian-kajian terdahulu yang dikorelasikan dengan geometri sungai hasil pengukuran. Persamaan utama dari referensi yang terpilih adalah dari Carlston $\lambda=106 Q^{0,46}$ dan Anderson $\lambda=39 Q^{0,39}$. Dari dua persamaan-persamaan ini kemudian didapat persamaan baru Kuntjoro $\lambda=105 Q^{0,517}$. Ketika ketiga persamaan tersebut diaplikasikan kedalam meander sungai Brantas di Ngadiluwih Kediri untuk menguji kesesuaian formula. Dari uji kesesuaian tersebut, yang ditinjau dari standar deviasi, dinyatakan bahwa model Anderson adalah yang paling tidak sesuai, kemudian model Carlston, dan model Kuntjoro adalah yang paling sesuai dengan standar deviasi $\lambda=0,07, a=123,36, B=2,34$ dan $r=11,70$
\end{abstract}

Kata kunci: debit, geometri, meander, dan sungai.

\section{Pendahuluan}

Pergeseran alur sungai adalah suatu proses di dalam sungai yang berkaitan dengan erosi pada satu tebing dan dasar sungai di satu sisi disertai dengan pendangkalan di sisi lain. Fluktuasi debit yang terjadi sepanjang tahun menyebabkan perubahan tanah dasar dan tebing sungai, perubahan fluktuasi debit kemungkinan juga akan menyebabkan cepatnya pergerakan alur sungai. Kondisi alam membentuk aliran sungai dengan geometri sesuai dengan tuntutan debit yang terjadi dan topografi yang ada sehingga menjadikan sungai tidak mungkin terlihat lurus sempurna. Ketidaklurusan sungai ini menyebabkan terjadinya arus helik (helical flow) (Chow, 1959) yang mempercepat terjadinya belokan-belokan dan lengkungan-lengkungan sungai. Pada alur sungai bermeander ini ancaman keamanan bangunan persungaian menjadi lebih nyata, hal ini terlihat bahwa pergerakan alur sungai bermeander lebih

Jurnal APLIKASI: Media Informasi \& Komunikasi Aplikasi Teknik Sipil Terkini Halaman 31 
cepat dari pada yang terjadi pada alur yang relatif lurus.

Besaran debit dengan karakteristik topografi di lokasi-lokasi tertentu pada alur sungai Brantas menyebabkan terbentuknya meander-meander sungai, seperti di segmen Ngadiluwih Kediri. Makalah ini adalah kajian awal tentang hubungan antara debit yang terjadi dengan geometri sungai pada tinjauan khusus meander sungai Brantas di Ngadiluwih Kediri berdasarkan hasil kajian-kajian terdahulu yang dikorelasikan dengan geometri sungai hasil pengukuran.

\section{Metodologi}

\subsection{Hubungan Antara Debit $(Q)$ dengan Panjang Meander $(\lambda)$}

Geometri meander sungai seperti ditunjukkan pada gambar 1 H. J. Overbeek, 1967) dari penelitiannya mendapatkan hubungan antara panjang meander ( $\lambda$ dalam feet) dengan debit banjir tahunan (Qma dalam $c f s$ ) yang dikutip dalam Shen (1970) "River Mechanics" (Harrell, 2003), dinyatakan dalam persamaan:

$\lambda=30 Q m a^{0,5}$

Carlston (1965) menemukan hubungan antara panjang meander dengan debit tahunan rata-rata ( $Q m$ dalam $c f s)$ yang dikutip dalam "River Mechanics" (Harrell, 2003), dinyatakan dalam persamaan:

$\lambda=106 Q m^{0,46}$

Hubungan debit dengan dimensi meander (Harrell, 2003), dinyatakan dalam persamaan:
$Q=\frac{b, d, \lambda}{S}$

Jika debit dihubungkan dengan kandungan sedimen dan sinousitas meander maka hubungan dinyatakan dalam "River Mechanics" (Harrell, 2003):

$Q_{S}=\frac{b, \lambda, S}{d, P}$

Dimana:

$Q s=$ prosentase kandungan sedimen total

$P=$ sinousitas

Persamaan empiris untuk panjang gelombang $(\lambda)$ dan amplitudo meander (a) terhadap lebar penuh sungai $(B)$ menurut Leopold dan Wolman (1960) dan Shen (1970), dinyatakan sebagai berikut:

$\lambda=10,9 B^{1,01}$

$a=2,7 B^{1,1}$

$\lambda=4,7 r_{c}^{0,98}$

Harrell (2003) dan Shen (1970):

$M=2 \pi B$

Dimana:

$M=$ panjang sungai satu gelombang meander

Anderson (1967), Shen (1970) dan Indratmo (1997) memprediksi panjang gelombang meander berdasarkan oscilasi komponen kecepatan transversal yang menyebabkan kenaikan air pada bagian luar tikungan dinyatakan dalam persamaan:

$\frac{\lambda}{A^{12}}=72 \pi^{0,52}$

$\lambda=39 Q^{0,39}$ 
dimana:

$A=$ luas penampang aliran

$\lambda=$ panjang gelombang meander

$Q=$ debit aliran

Persamaan 9 bisa ditulis:

$\lambda=72 \pi^{0,52} A^{12}$

Persamaan 10 dan persamaan 11 ditulis dalam:

$$
\begin{aligned}
& 39 Q^{0,39}=72 \pi^{0,52} A^{12} \\
& A=\left(\frac{39 Q^{0,39}}{72 \pi^{0,52}}\right)^{\frac{1}{12}} \\
& r_{c}=\left(\frac{39 Q^{0,39}}{4,7}\right)^{\frac{1}{0,97}}
\end{aligned}
$$

Kennedy (1895) adalah orang pertama yang melakukan pemodelan hidraulik persungaian, dia mencari hubungan antara kecepatan aliran rata-rata dengan kedalaman air rata-rata (Shen, 1970). Kemudian penelitian yang dilakukan Blench (1957) (Shen, 1970) dan Lane (1957) (Harrell, 2003 dan Jansen, 1979) mengarahkan penelitian mereka pada geometrik dan hidraulik sungai-sungai aluvial. Menerapkan teori rezim meskipun hanya pada kondisi sungai yang terbatas, yang kemudian menjadi dasar pembentukan model geometri hidraulik saluran empiris terbuka alami dengan aliran yang sangat variabel dan geometri saluran yang sangat bervariasi. Hubungan geometri hidraulik dengan variabel tergantung dari lebar sungai, kedalaman rata-rata, kecepatan, kemiringan dan kekasaran yaitu, hambatan aliran Manning atau faktor gesekan Darcy-Weisbach. Kemudian dikembangkan oleh Leopold dan
Maddock (1954) (Shen, 1970 dan Indratmo, 1997) untuk mendapatkan hubungan dengan debit terukur:

$\left.\begin{array}{l}W=a Q^{b}, \\ D=c Q f, \\ V=k Q m, \\ G=t Q z, \\ n=r Q v\end{array}\right\}$

dimana: $W$ : lebar sungai, $D$ : kedalaman rata-rata, $V$ : kecepatan, $G$ : gradien, $n$ : kekasaran dan $Q$ : debit. $a, c, k, t$ dan $r$ : keofisien intercept, dan $b, f, m, z$ dan $y$ : koefesien eksponen.

\subsection{Prosedur Penentuan Geometri Sungai}

Perhitungan geometri meander sungai ditentukan dengan langkah-langkah sebagai berikut:

1. Data debit sungai.

2. Mengacu pada persamaan meander Carlston dan Anderson dengan menyesuaikan koefesien dan eksponen untuk mendapatkan hasil yang mendekati kondisi real di lapangan.

3 . Penentuan panjang gelombang meander $(\lambda)$ dengan persamaan 10 .

4. Penentuan jari-jari lengkung meander $\left(r_{c}\right)$ dengan persamaan 14.

5. Penentuan lebar sungai $(B)$ sungai dengan persamaan 5 .

6. Penentuan amplitudo meander (a) dengan persamaan 6 .

7. Penentuan luas penampang basah sungai $(A)$ dengan persamaan 13.

\subsection{Lengkung Meander Sungai Brantas di Ngadiluwih}

Alur sungai Brantas di di Desa Purwodadi Kecamatan Ngadiluwih, Kabupaten Kediri sesuai dengan Peta yang 
bersumber pada Bakosurtanal seperti yang terlihat pada gambar 1, dengan pemilihan meander sungai ditunjukkan pada gambar 2, dan lebih detail ditunjukkan pada gambar 3 .
Desa Purowodadi, Kecamatan Ngadiluwih

Gambar 1. Alur Sungai Brantas di Ngadiluwih Kediri

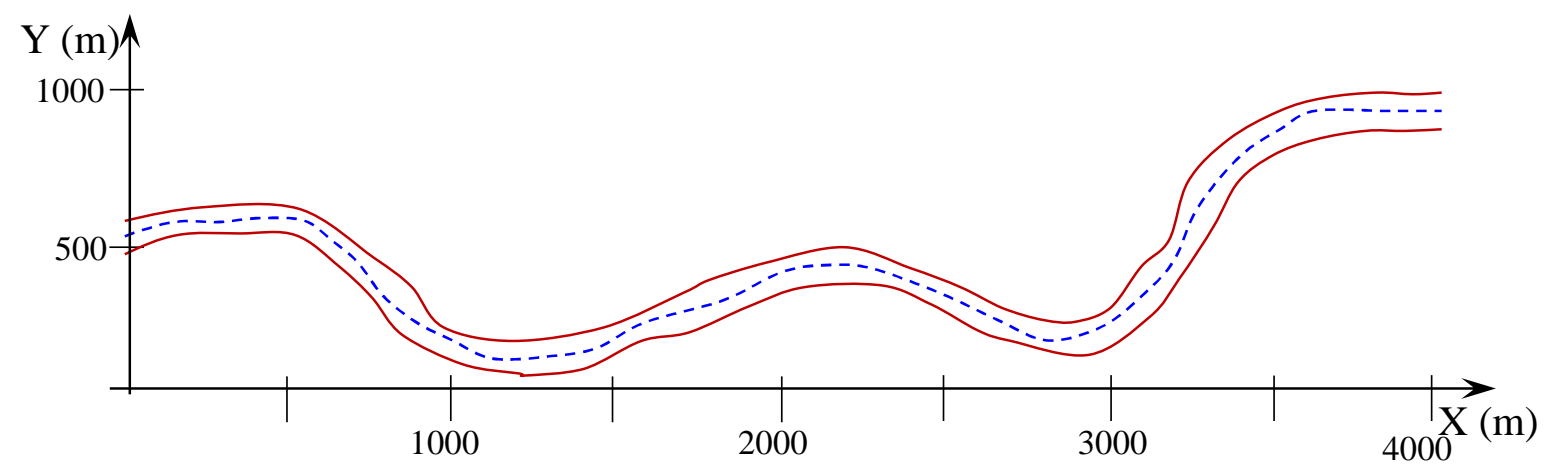

Gambar 2. Pemilihan Segmen Meander Sungai di Ngadiluwih Kediri 


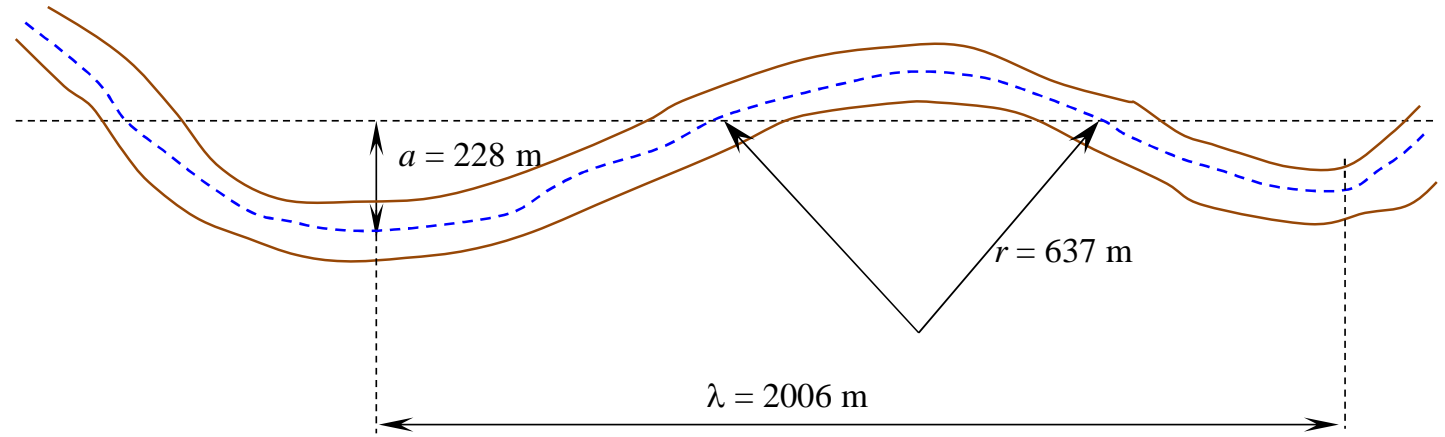

Gambar 3. Parameter Meander Sungai Brantas di Ngadiluwih Kediri

\section{Hasil dan Pembahasan}

\subsection{Pemilihan Model}

Model yang diajukan Leopold dan Maddock (1954) tidak mengandung parameter geometri sungai bermeander, sehingga model ini tidak dipakai dalam pengembangan hubungan antara debit dengan geometri sungai bermenader.

Model Leopold dan Wolman (1960), dipakai untuk menghitung parameterparameter dari model yang sudah dibentuk dengan urutan yang diuraikan dalam sub bab 2.2.

\subsection{Hubungan Parameter Meander Dengan Data Debit}

Dengan menggunakan kaidah-kaidah yang diuraikan dalam hubungan antar parameter dengan debit $\left(Q \mathrm{~m}^{3} /\right.$ detik) ditinjau dari model-model meander yang sudah ada seperti yang terlihat pada Tabel 1 dengan $\mathrm{Q}=300,35 \mathrm{~m}^{3} / \mathrm{dt}$ dan $s=0,0063$, model-model tersebut diterapkan untuk kondisi meander sungai Brantas di Ngadiluwih.

Hasil penerapan model-model tersebut menunjukkan tingkat kesesuaian model dengan kondisi sungai bermeander yang dipakai sebagai sungai uji. Kemudian tingkat kesesuaian dari model-model tersebut dipakai dasar untuk menentukan model hubungan antar parameter meander dengan debit yang akan diciptakan ini. Hasil uji kesesuaian model-model yang sudah ada dan model yang diciptakan dengan data hasil pengukuran lapangan dinyatakan dalam standar deviasi seperti yang ditunjukkan ada tabel 2. dan Gambar 4a, b, c, dan d.

Model standar deviasi dengan parameter meander hasil pengukuran:

a. Model yang diajukan Carlston:

- Nilai $\lambda$ pada kesesuaian dengan standar deviasi 384,53.

- Nilai a pada kesesuaian dengan standar deviasi 132,17.

- Nilai $B$ pada kesesuaian dengan standar deviasi 103,25.

- Nilai $r$ pada kesesuaian dengan standar deviasi 187,76.

b. Model yang diajukan Anderson:

- Nilai $\lambda$ pada kesesuaian dengan standar deviasi 1163,31.

- Nilai $a$ pada kesesuaian dengan standar deviasi 152,33.

- Nilai $B$ pada kesesuaian dengan standar deviasi 103,25.

- Nilai $r$ pada kesesuaian dengan standar deviasi 388,40. 
Tabel 1. Hubungan antara debit (Q) dengan parameter meander

\begin{tabular}{ccccccc}
\hline & $\lambda(\mathrm{m})$ & & $a(\mathrm{~m})$ & $\mathrm{B}(\mathrm{m})$ & $\mathrm{r}(\mathrm{m})$ \\
\hline Pengukuran & Model & $2.006,03$ & 228,33 & 178,00 & Model & 637,09 \\
\hline Carlston & $\lambda=106 \mathrm{Qm}^{0,46}$ & $1.462,23$ & 41,42 & 31,98 & $\mathrm{r}=((1 / 4,7) \mathrm{Q})^{(1 / 0,97)}$ & 371,55 \\
\hline Anderson & $\lambda=39 \mathrm{Q}^{0,39}$ & 360,86 & 12,91 & 31,98 & $\mathrm{r}=((1 / 4,7) \mathrm{Q})^{(1 / 0,97)}$ & 87,81 \\
\hline Kuntjoro & $\lambda=105 \mathrm{Q}^{0,517}$ & $2.005,04$ & 53,88 & 174,69 & $\mathrm{r}=((1 / 5,5) \mathrm{Q})^{(1 / 0,91)}$ & 653,31 \\
\hline
\end{tabular}

Tabel 2. Standar Deviasi Kesesuaian Model Dengan Kondisi Lapangan

\begin{tabular}{ccccc}
\hline & $\begin{array}{c}\text { Deviasi Panjang } \\
\text { Gelombang }(\lambda)\end{array}$ & $\begin{array}{c}\text { Deviasi Amplitudo } \\
(a)\end{array}$ & $\begin{array}{c}\text { Deviasi Lebar Sungai } \\
(\mathrm{B})\end{array}$ & $\begin{array}{c}\text { Deviasi Jari-jari } \\
\text { Lengkung }(r)\end{array}$ \\
\hline Carlston & 384,53 & 132,17 & 103,25 & 187,76 \\
\hline Anderson & 1163,31 & 152,33 & 103,25 & 388,40 \\
\hline Kuntjoro & 0,70 & 123,36 & 2,34 & 11,47 \\
\hline
\end{tabular}

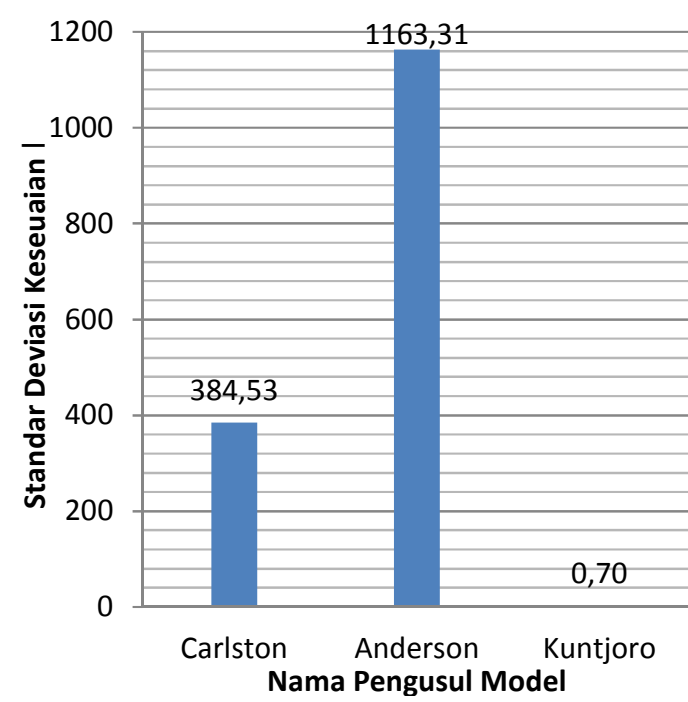

Gambar 4a. Standar Deviasi $\lambda$ Kesesuaian Model Dengan Kondisi Lapangan

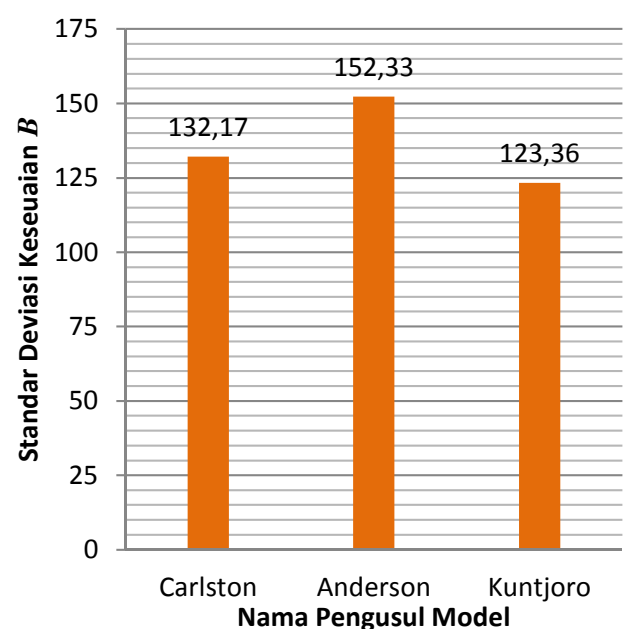

Gambar 4b. Standar Deviasi $B$ Kesesuaian Model Dengan Kondisi Lapangan

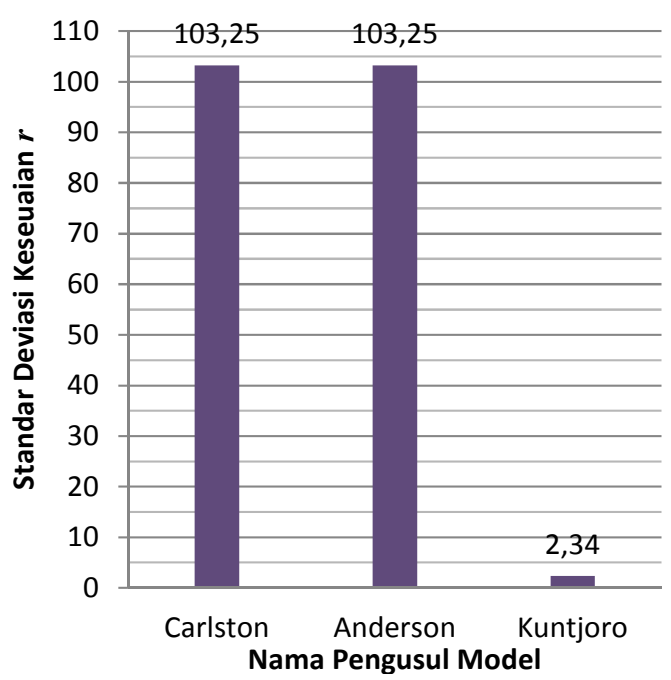

Gambar 4c. Standar Deviasi $a$ Kesesuaian Model Dengan Kondisi Lapangan

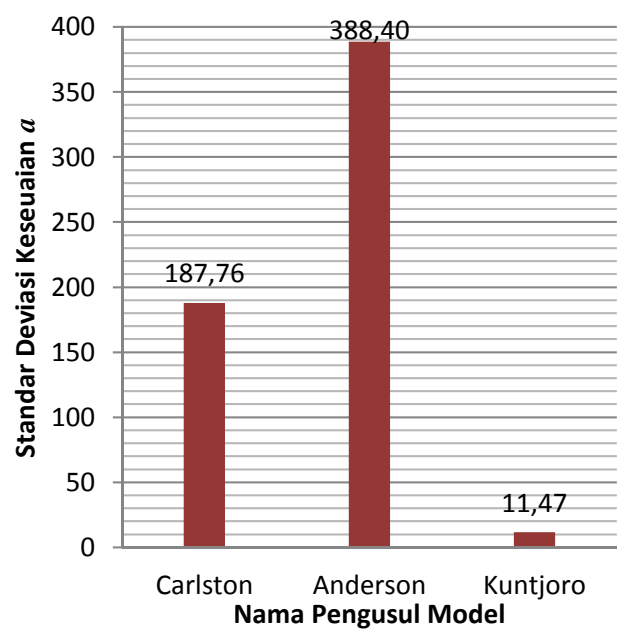

Gambar 4d. Standar Deviasi $a$ Kesesuaian Model Dengan Kondisi Lapangan 
c. Model yang diajukan Kuntjoro

- Nilai $\lambda$ pada kesesuaian dengan standar deviasi 0,07

- Nilai a pada kesesuaian dengan standar deviasi 123,36

- Nilai $B$ pada kesesuaian dengan standar deviasi 2,34

- Nilai $r$ pada kesesuaian dengan standar deviasi 11,47

\section{Simpulan}

Dari uji kesesuaian yang ditinjau dari standar deviasi terhadap hasil pengukuran di lapangan maka bisa dinyatakan bahwa:

1. Model Anderson adalah yang paling tidak sesuai dengan penyimpangan paling besar yaitu: $\lambda=1163,31, a=$ $152,33, B=103,25$, dan $r=388,40$.

2. Kemudian model Carlston dengan penyimpangan $\lambda=384,53, a=$ $132,17, B=103,25$, dan $r=187,76$.

3. Yang paling sesuai adalah model Kuntjoro dengan standar deviasi $\lambda=$ $0,07, a=123,36, B=2,34$, dan $r=$ 11,47 .

\section{Daftar Pustaka}

Chow, Ven Te. 1959. Open Channel Hydraulics, McGraw-Hill Kogakusha, LTD. Tokyo.

Harrell, C., B.K. Ghosh and R.O. Bowden. 2003. Simulation Using Promodel, 2nd ed., McGraw-Hill. Singapore.

Hinze J. Overbeek, 1967, Secundary Curents in Wall Turbulence, Kyoto, 1966, also: Phisics of Fluids suppl. 10,9, part 2, S122-S125
Indratmo, Soekarno. 1997. Morfologi dan Hidraulika Sungai. Bandung: ITB.

Jansen, L. Van Bendegom, J van den Berg, M de Vries, A Zanen. 1979. Principles of River Engineering The non-tidal alluvial river. London: Pitman Publishing Limited.

Kennedy, 1895, The Preentions of Silting in Irrigaion Canals, Minutes of Proc. Inst. Ci. Eng. London, 119, sect. II, 281-290

Leopold, L. B and Wolman M. G. 1960, "River Meander.", Bull Geol. Soc. Am., 71, 769 - 794

Leopold L. B. and Maddock, T, 1954, The Flood Control Controversy. The Ronald Press Co., New York

Overbeek, H.J. 1978. Revier Engineering and Flood Protection. Bangkok: Asian Institut of Tecknology.

Shen, Hsieh Wen. 1970. River Mechanics volume I, H. W Shen Book Company. Colorado. 
Halaman ini sengaja dikosongkan 